\title{
Determinants of Weight Loss Dieting Among Adolescents: A Longitudinal Analysis
}

\author{
Vânia Mendes ${ }^{\mathrm{a}, \mathrm{b}, *}$, Joana Araújo, M.P.H. ${ }^{\mathrm{a}, \mathrm{b}}$, Carla Lopes, Ph.D. ${ }^{\mathrm{a}, \mathrm{b}}$, and Elisabete Ramos, Ph.D. ${ }^{\mathrm{a}, \mathrm{b}}$ \\ ${ }^{a}$ Department of Clinical Epidemiology, Predictive Medicine and Public Health, University of Porto Medical School, Porto, Portugal \\ ${ }^{\mathrm{b}}$ Institute of Public Health, University of Porto, Porto, Portugal
}

Article history: Received June 5, 2013; Accepted December 2, 2013

Keywords: Dieting; Adolescents; BMI; Body dissatisfaction; Depressive symptomatology; Health-related behaviors

\section{A B S T R A C T}

Purpose: To prospectively assess characteristics associated with dieting behaviors in adolescence. Methods: We analyzed 1,640 adolescents evaluated at 13 and 17 years old (EPITeen cohort), Porto, Portugal. Dieting was assessed only at 17 years, as self-reported frequency of dieting to lose weight in the previous 12 months. The association between participants' characteristics and dieting was summarized using multinomial logistic regression for girls and binary logistic regression for boys.

Results: Dieting at 17 years old was significantly more prevalent in girls than in boys (respectively $27.6 \%$ and $10.5 \%$ for occasional dieting and $12.2 \%$ and $2.6 \%$ for frequent dieting). In both sexes, overweight and obese adolescents were significantly more likely to engage in dieting but body dissatisfaction was the strongest determinant among girls. Furthermore, dieting frequency also increased with depressive symptomatology and among those involved in health compromising behaviors.

Conclusions: Besides body mass index, body image concerns and depressive symptomatology predict dieting throughout adolescence.

(c) 2014 Society for Adolescent Health and Medicine. All rights reserved.

\section{IMPLICATIONS AND CONTRIBUTION}

Dieting in adolescence can have harmful consequences. Among girls, body dissatisfaction was the strongest determinant of this behavior. This highlights the importance of promoting a healthy body image beginning in early adolescence and the challenge of developing obesity prevention strategies that do not cause excessive weight concerns.
Throughout adolescence body image becomes one of the major components of self-esteem, enhancing adolescents' desire to pursue the ideal body standard. This ideal is often impossible to attain, resulting in body dissatisfaction that peaks during adolescence [1].

Among adolescents, dieting has often been described as one of the most common strategies for weight control. Although it sometimes implies healthier choices, dieting may compromise adequate nutrient intake and nutritional status [2]. This behavior has been associated with low self-esteem, depression and suicidal thoughts [3], and with the onset of eating disorders

\footnotetext{
Conflicts of interest: No authors have personal or financial conflicts of interest to declare.

* Address correspondence to: Vânia Mendes, Instituto de Saúde Pública da Universidade do Porto, Rua das Taipas, 135, 4050-600 Porto, Portugal.

E-mail address: vaniamendes@med.up.pt (V. Mendes).
}

[4]. Furthermore, dieting promotes weight gain [5]. This becomes even more relevant because dieting seems to track into adulthood [6].

Previous studies have evaluated factors associated with dieting and this information provides useful insight in developing prevention strategies. However, results are often limited to females and do not establish a temporal relationship. Our aim was to prospectively assess characteristics at 13 years old associated with dieting at 17 years old, in a unique sample of Portuguese adolescents.

\section{Methods}

This study was developed in a population-based cohort (EPITeen), which included adolescents born in 1990 enrolled in public and private schools of Porto, Portugal, in 2003/2004 [7]. The information was collected by self-administered questionnaires 
Table 1

Participants' characteristics at 13 years old according to the reported frequency of dieting at 17 years old, by sex

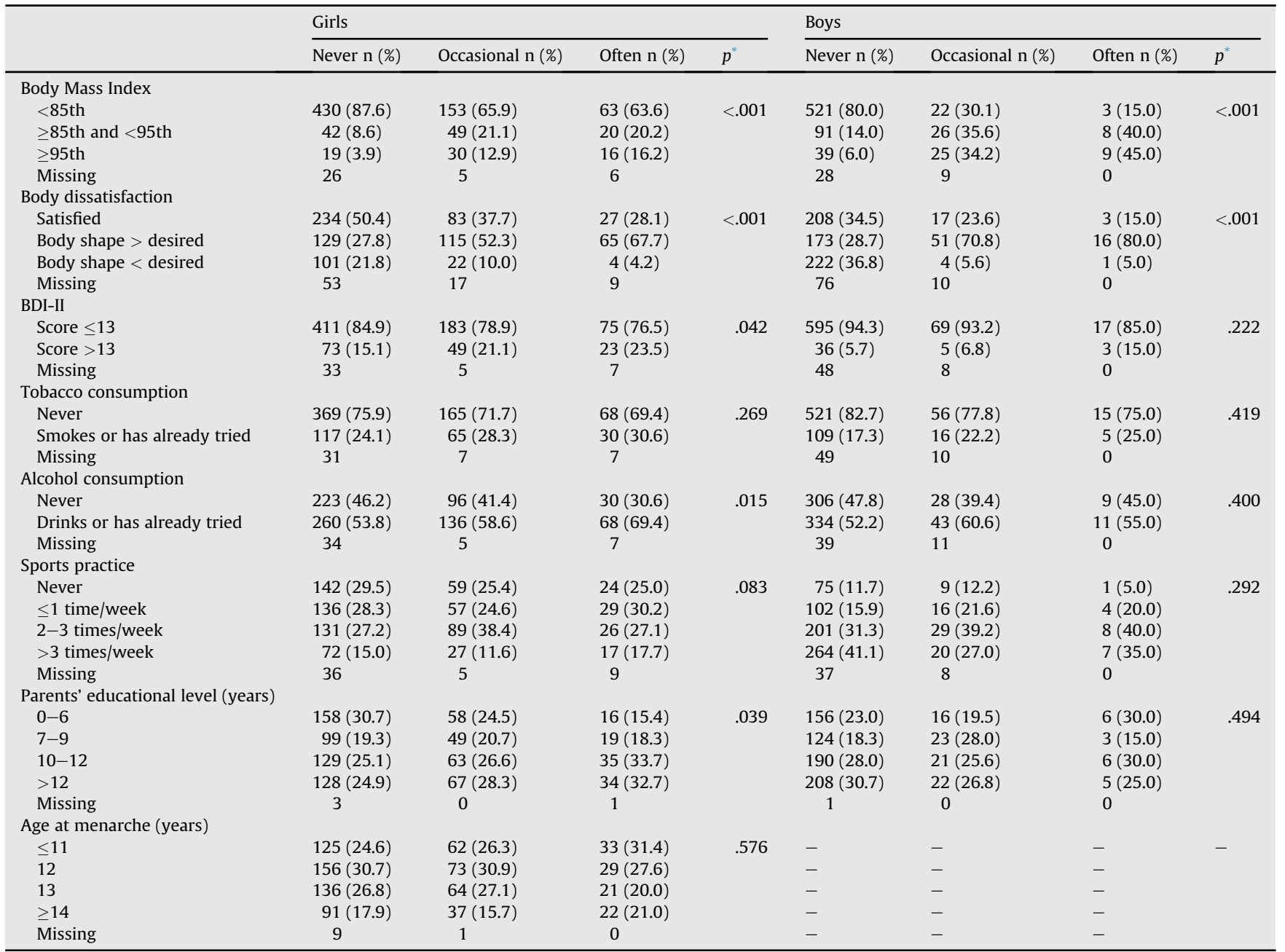

$* p$ values are based on $\chi^{2}$ statistics.

and a physical examination. The second evaluation was performed during 2007/2008, using similar procedures.

\section{Data collection}

Dieting was assessed only at 17 years of age, using the question, "How many times have you dieted (changed the way you eat in order to lose weight) in the previous 12 months?" According to the variable distribution participants were categorized into three groups: "never," "occasional" (1-4 times), and "often" ( $\geq 5$ times). In boys "often" and "occasional" categories were merged for the regression analysis.

Body shapes were evaluated using the Stunkard's Figure Rating Scale [8]. Body dissatisfaction was assessed as the difference between self-perceived and desired shapes. Participants were classified as: satisfied (difference $=0$ ); having a larger body shape than that desired (difference $\geq 1$ ), and having a thinner body shape than that desired (difference $\leq-1$ ).

Depressive symptomatology was evaluated by the Beck Depression Inventory-II (BDI-II) and a score $>13$ defined the presence of relevant depressive symptoms [9]. Parental educational level was measured as the number of successfully completed years of formal schooling. Sports practice was assessed by the frequency of extracurricular sports for at least 20 minutes.

Weight and height were obtained in light indoor clothes and without shoes. Participants were classified according to the ageand sex-specific Body Mass Index (BMI) references from the U.S. Centers for Disease Control and Prevention [7]. Because less than $2 \%$ of the participants were classified as underweight, the lower category was $<85$ th percentile.

\section{Participants}

At baseline, 2,160 adolescents agreed to participate (participation rate of $77.5 \%$ ) [7]. Of these, 1,716 (79.4\%) participated in the second evaluation. After the exclusion of 76 individuals due to missing data on dieting, we included 1,640 participants ( $47.6 \%$ females).

The study protocol was approved by The Ethics Committee of Hospital de S. João and a written informed consent for each evaluation was obtained from parents and adolescents. 
Table 2

Associations between participants' characteristics at 13 years old and dieting at 17 years old

\begin{tabular}{|c|c|c|c|c|c|c|c|c|c|}
\hline & \multicolumn{6}{|l|}{ Girls } & \multicolumn{3}{|l|}{ Boys } \\
\hline & \multicolumn{2}{|l|}{ Crude OR $(95 \% \mathrm{CI})$} & \multicolumn{2}{|c|}{ Model $1^{\text {a }}$ OR $(95 \% \mathrm{CI})$} & \multicolumn{2}{|c|}{ Model $2^{\mathrm{b}}$ OR $(95 \% \mathrm{CI})$} & \multirow{2}{*}{$\begin{array}{l}\text { Crude OR }(95 \% \mathrm{CI}) \\
{\text { Occasional }+ \text { Often }^{c}}^{\text {c }}\end{array}$} & \multirow{2}{*}{$\frac{\text { Model } 1^{\mathrm{a}} \text { OR }(95 \% \mathrm{CI})}{{\text { Occasional }+ \text { Often }^{\mathrm{c}}}^{\mathrm{c}}}$} & \multirow{2}{*}{$\frac{\text { Model } 2^{\mathrm{b}} \text { OR }(95 \% \mathrm{CI})}{{\text { Occasional }+ \text { Often }^{\mathrm{c}}}^{\mathrm{c}}}$} \\
\hline & Occasional $^{\mathrm{c}}$ & Often $^{c}$ & Occasional $^{\mathrm{C}}$ & Often $^{c}$ & Occasional $^{\mathrm{C}}$ & Often $^{c}$ & & & \\
\hline \multicolumn{10}{|l|}{ Body Mass Index } \\
\hline$<85$ th & 1 & 1 & 1 & 1 & 1 & 1 & 1 & 1 & 1 \\
\hline$\geq 85$ th and $<95$ th & $3.28(2.09-5.15)$ & $3.25(1.79-5.89)$ & $2.93(1.75-4.91)$ & $2.84(1.43-5.65)$ & $2.24(1.40-3.59)$ & $2(1.08-3.72)$ & 7.79 (4.44-13.66) & $3.94(2.04-7.59)$ & $5.71(3.18-10.26)$ \\
\hline$\geq 95$ th & $4.44(2.43-8.16)$ & $5.75(2.81-11.76)$ & $3.84(1.66-8.90)$ & $2.76(.94-8.07)$ & $2.64(1.41-4.95)$ & $2.96(1.40-6.24)$ & $18.17(9.87-33.45)$ & $5.34(2.41-11.80)$ & $10.55(5.28-21.07)$ \\
\hline \multicolumn{10}{|c|}{ 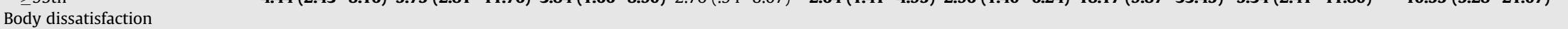 } \\
\hline Satisfied & 1 & 1 & 1 & 1 & 1 & 1 & 1 & 1 & 1 \\
\hline Body shape $>$ desired & $2.51(1.76-3.58)$ & $4.37(2.66-7.18)$ & $2.12(1.46-3.09)$ & $3.59(2.13-6.06)$ & $1.79(1.23-2.61)$ & $2.91(1.74-4.90)$ & $4.03(2.35-6.90)$ & $2.08(1.15-3.80)$ & $2.74(1.52-4.94)$ \\
\hline Body shape $<$ desired & $.61(.36-1.04)$ & $.34(.12-1.01)$ & $.64(.38-1.09)$ & $.35(.12-1.02)$ & $.87(.50-1.53)$ & $.47(.16-1.40)$ & $.23(.09-.64)$ & $.32(.12-.88)$ & $.26(.10-.73)$ \\
\hline \multicolumn{10}{|l|}{ BDI-II } \\
\hline Score $\leq 13$ & 1 & 1 & 1 & 1 & 1 & 1 & 1 & 1 & 1 \\
\hline Score $>13$ & $1.51(1.01-2.25)$ & $1.73(1.02-2.93)$ & $1.53(1.01-2.29)$ & $1.81(1.06-3.11)$ & $1.30(.85-1.99)$ & $1.41(.81-2.46)$ & $1.54(.69-3.42)$ & $2.13(.87-5.17)$ & $2.20(.93-5.19)$ \\
\hline \multicolumn{10}{|l|}{ Tobacco consumption } \\
\hline Never & 1 & 1 & 1 & 1 & 1 & 1 & 1 & 1 & 1 \\
\hline Smokes or has already tried & $1.24(.87-1.77)$ & $1.39(.86-2.24)$ & $1.27(.89-1.82)$ & $1.46(.90-2.38)$ & $1.15(.80-1.67)$ & $1.32(.80-2.17)$ & $1.41(.83-2.40)$ & $1.44(.80-2.60)$ & $1.22(.70-2.12)$ \\
\hline \multicolumn{10}{|l|}{ Alcohol consumption } \\
\hline Never & 1 & 1 & 1 & 1 & 1 & 1 & 1 & 1 & 1 \\
\hline \multirow{2}{*}{\multicolumn{10}{|c|}{ 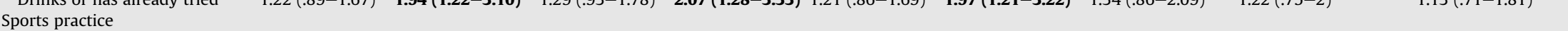 }} \\
\hline & & & & & & & & & \\
\hline Never & 1 & 1 & 1 & 1 & 1 & 1 & 1 & 1 & 1 \\
\hline$\leq 1$ time/week & $1.01(.65-1.56)$ & $1.26(.70-2.28)$ & $1(.64-1.55)$ & $1.18(.64-2.16)$ & $.89(.11-.79)$ & $1.11(.60-2.06)$ & $1.47(.65-3.32)$ & $1.03(.41-2.56)$ & $1.13(.48-2.68)$ \\
\hline $2-3$ times/week & $1.64(1.09-2.45)$ & $1.17(.64-2.15)$ & $1.67(1.10-2.52)$ & $1.23(.66-2.26)$ & $1.61(1.04-2.48)$ & $1.16(.62-2.18)$ & $1.38(.65-2.92)$ & $1.18(.52-2.70)$ & $1.26(.57-2.77)$ \\
\hline$>3$ times/week & $.90(.53-1.54)$ & $1.40(.71-2.77)$ & $.95(.55-1.63)$ & $1.47(.73-2.95)$ & $.85(.49-1.50)$ & $1.37(.67-2.80)$ & $.77(.36-1.66)$ & $.63(.27-1.47)$ & $.73(.32-1.63)$ \\
\hline \multicolumn{10}{|c|}{ Parents' educational level (years) } \\
\hline $0-6$ & $.70(.46-1.07)$ & $.38(.20-.72)$ & $.62(.40-.95)$ & $.30(.26-.59)$ & . $75(.48-1.17)$ & $.39(.20-.77)$ & $1.09(.60-1.98)$ & $1.21(.62-2.35)$ & $1.37(.72-2.58)$ \\
\hline $7-9$ & $.95(.60-1.49)$ & $.72(.39-1.34)$ & $.84(.53-1.34)$ & $.60(.32-1.14)$ & $.97(.60-1.56)$ & $.72(.38-1.38)$ & $1.62(.90-2.89)$ & $1.77(.92-3.41)$ & $1.90(1.02-3.54)$ \\
\hline $10-12$ & $.93(.61-1.42)$ & $1.02(.60-1.74)$ & $.88(.57-1.35)$ & $.89(.51-1.53)$ & $.90(.58-1.40)$ & $.98(.56-1.70)$ & $1.10(.62-1.93)$ & $.88(.47-1.65)$ & $1.10(.61-1.99)$ \\
\hline$>12$ & 1 & 1 & 1 & 1 & 1 & 1 & 1 & 1 & 1 \\
\hline \multicolumn{10}{|l|}{ Age at Menarche (years) } \\
\hline$\leq 11$ & $1.22(.75-1.99)$ & $1.09(.60-2)$ & $1.07(.65-1.77)$ & $.93(.50-1.72)$ & $1.03(.62-1.73)$ & $.91(.48-1.71)$ & - & - & - \\
\hline 12 & $1.15(.72-1.85)$ & $.77(.42-1.42)$ & $1.21(.75-1.95)$ & $.69(.37-1.30)$ & $1.06(.64-1.75)$ & $.72(.38-1.37)$ & - & - & - \\
\hline 13 & $1.16(.71-1.88)$ & $.64(.33-1.23)$ & $1.16(.71-1.89)$ & $.60(.31-1.16)$ & $1.11(.66-1.85)$ & $.62(.31-1.22)$ & - & - & - \\
\hline$\geq 14$ & 1 & 1 & 1 & 1 & 1 & 1 & & & \\
\hline
\end{tabular}

Statistically significant results are shown in bold.

${ }^{a}$ Model 1: adjusted for BMI at 17 years old.

b Model 2: adjusted for body dissatisfaction at 17 years old.

c Reference class: "never." 


\section{Statistical analysis}

Statistical analysis was performed using SPSS Statistics, version 19.0 for Windows (IBM, Armonk, NY). Odds ratio (OR) and respective $95 \%$ confidence intervals (95\% CI) were estimated using multinomial logistic regression for girls and binary logistic regression for boys. Two regression models were presented, one adjusted for BMI at 17 years of age (model 1), the other adjusted for body dissatisfaction at 17 years of age (model 2 ).

\section{Results}

At 17 years old, $27.6 \%$ of girls and $10.5 \%$ of boys reported dieting occasionally. Values for dieting often were $12.2 \%$ and $2.6 \%$, respectively. Participants' characteristics according to dieting frequency are described in Table 1.

In both sexes, BMI and body dissatisfaction at 13 years old appeared as major determinants of dieting at 17 years of age, even after adjustment for their values at 17 years. The presence of depressive symptoms was also positively associated with dieting in both sexes, but it was significant only among girls. Alcohol use at 13 years of age is associated with a higher probability of dieting at 17 years in girls. We found a higher probability of dieting among daughters of more educated parents (Table 2).

\section{Discussion}

In this sample, more than $39 \%$ of girls and $13 \%$ of boys reported dieting in the previous year. Among girls, this behavior is mainly associated with body image concerns and we found a high dieting prevalence even among those who were normal weight, which may be explained by the strong social pressure to be thin experienced by females [1]. Additionally, the increase of body fat mass that occurs in girls throughout adolescence may prompt them to engage in weight loss behaviors. In contrast, for males, puberty increases lean body mass, which inclines boys toward the desired muscular ideal and, therefore, dieting is not an expected practice. Accordingly, in our study, overweight was the major determinant of dieting among boys.

We observed that adolescents who reported depressive symptoms at 13 years of age had higher odds of dieting later on, which may reflect an attempt to boost self-esteem [3].

Dieting has also been described as more prevalent among those who engage in health compromising behaviors such as alcohol consumption and smoking [3]. We found this effect from early adolescence, particularly among girls. In this context, dieting may also result from the desire to be socially accepted, as an attempt to decrease the negative affection toward the self $[1,3]$.

Girls from families with higher socioeconomic status were more likely to diet, probably because they may experience greater levels of drive for thinness and body dissatisfaction [10]. However, results in the literature are conflicting $[3,10]$.
Some limitations of our study need to be acknowledged. Because we did not further characterize dieting, it is not possible to understand what these adolescents really do when they state they are dieting, nor is it possible to differentiate whether this is a desirable and properly monitored response to overweight. Nevertheless, the strong association of body dissatisfaction with dieting among girls supports that this is an undesirable behavior, at least for females. Despite the longitudinal approach of our analysis, because data concerning dieting frequency was not available at 13 years old, the temporal relationship is difficult to establish.

In conclusion, we found a high prevalence of dieting for weight loss, especially among girls. The desire to be thinner in early adolescence was the strongest determinant of dieting later in adolescence. These results highlight the challenge of developing efforts to build up adolescents' self-esteem and to deconstruct idealized body standards, placing focus on healthpromoting behaviors rather than appearance-related behaviors.

\section{Acknowledgments}

Results of this study were presented as a poster at the European Congress of Epidemiology in September 2012.

\section{Funding Sources}

This work was supported by the Portuguese Foundation for Science and Technology: FCOMP-01-0124-FEDER-015750 (Ref. FCT PTDC/SAU-EPI/115254/2009) and SFRH/BD/78153/2011 to JA.

\section{References}

[1] Littleton HL, Ollendick T. Negative body image and disordered eating behavior in children and adolescents: What places youth at risk and how can these problems be prevented? Clin Child Fam Psychol Rev 2003;6: $51-66$.

[2] Guest J, Bilgin A, Pearce R, et al. Evidence for under-nutrition in adolescent females using routine dieting practices. Asia Pac J Clin Nutr 2010;19: $526-33$.

[3] Neumark-Sztainer D, Hannan PJ. Weight-related behaviors among adolescent girls and Boys: Results from a national survey. Arch Pediatr Adolesc Med 2000;154:569-77.

[4] Patton GC, Selzer R, Coffey C, et al. Onset of adolescent eating disorders: Population based cohort study over 3 years. Br Med J 1999;318:765-8.

[5] Lowe MR, Doshi SD, Katterman SN, et al. Dieting and restrained eating as prospective predictors of weight gain. Front Psychol 2013;4:577.

[6] Neumark-Sztainer D, Wall M, Larson NI, et al. Dieting and disordered eating behaviors from adolescence to young adulthood: Findings from a 10-year longitudinal study. J Am Diet Assoc 2011;111:1004-11.

[7] Ramos E, Barros H. Family and school determinants of overweight in 13-year-old Portuguese adolescents. Acta Paediatr 2007;96:281-6.

[8] Stunkard AJ, Sorensen T, Schulsinger F. Use of the Danish Adoption Register for the study of obesity and thinness. Res Publ Assoc Res Nerv Ment Dis 1983;60:115-20.

[9] Coelho R, Martins A, Barros H. Clinical profiles relating gender and depressive symptoms among adolescents ascertained by the Beck Depression Inventory II. Eur Psychiatry 2002;17:222-6.

[10] Drewnowski A, Kurth CL, Krahn DD. Body weight and dieting in adolescence: Impact of socioeconomic status. Int J Eat Disord 1994;16:61-5. 